\title{
PENERAPAN KESELAMATAN DAN KESEHATAN KERJA (K3) PADAPEKERJAAN PEMBANGUNAN GEDUNG TAHAP II KANWILDIRJEN BEA DAN CUKAI JAWA TENGAH DAN D.I YOGYAKARTA
}

\author{
Himawan Ady Nugroho ${ }^{1 *}$, Hari Setijo Pudjihardjo, Muhammad Wahyu Hadi Saputro ${ }^{3}$ \\ Jurusan Teknik Sipil Fakultas Teknik Universitas Semarang, \\ Jl. Soekarno Hatta, Tlogosari, Semarang, Jawa Tengah, Indonesia \\ e-mail:himawan ady@yahoo.co.id
}

\begin{abstract}
Occupational safety and health is a very important thing in the world of work, because it can minimize the occurrence of work accidents and ensure the safety of workers both physically and spiritually. Because construction services are one sector that has a high risk of accident. So from that taken a research about the application of Occupational Health and Safety in the Construction Project Phase II of the Regional Office of the Directorate General of Customs and Excise Central Java and D.I Yogyakarta which is on Jl. A. Yani No. 139 in Semarang and carried out by the contractor. PT. Satriamas Karyatama-PT. Gala Tama. Because the project has a high level of vulnerability to the possibility of a work accident. In this study using a questionnaire of 35 respondents. After distributing the questionnaire and obtaining data from the respondents then calculated using the IKR formula. From the results of the research that has been done most of the respondents are workers with a percentage of $62.8 \%$ and more than five years of experience with ages 20-50 years and most of them have high school education equivalent with a percentage of $60 \%$. For the biggest safety and health guarantee, it is quite good and the most common cause of work accidents is the lack of awareness of the workers themselves while the rules applied are quite good. For PPE facilities that are often used the project helmet arrives and adheres to the $K 3$ signs. This means that the implementation of safety and health programs on the project have been implemented properly.
\end{abstract}

Keywords: occupational safety and health; construction; project; questionnaire distribution; research results.

\begin{abstract}
ABSTRAK
Jasa konstruksi adalah salah satu sektor yang memiliki resiko. Maka dari itu diambil penelitian tentang penerapan Keselamtan dan Kesehatan Kerja (K3) pada proyek Pembangunan Gedung Tahap II Kanwil Dirjen Bea dan Cukai Jawa Tengah dan D.I Yogyakarta yang berada di J. A. Yani No. 139 di kota Semarang dan dikerjakan oleh kontraktor KSO. PT. Satriamas Karyatama-PT. Gala Tama. Karena proyek tersebut memiliki tingkat kerawanan yang tinggi terhadap kemungkinan terjadinya kecelakaan kerja. Tujuan dari penelitian ini adalah untuk menganalisis Penerapan Keselamatan dan Kesehatan Kerja (K3 ). Pada Pekerjaan Pembangunan Gedung Tahap II Kanwil Dirjen Bea dan Cukai Jawa Tengah dan D.I. Yogyakarta. Pada penelitian ini menggunakan kuesioner sebanyak 35 responden.. Setelah menyebarkan kuesioner dan didapat data dari responden selanjutnya dihitung dengan menggunakan rumus IKR. Dari hasil penelitian yang telah dilakukan sebagian besar responden adalah pekerja dengan presentase $62.8 \%$ dan berpengalaman lebih dari lima tahun dengan usia 20-50 tahun dan sebagian besar berpendidikan SMA sederajat dengan presentase $60 \%$. Untuk jaminan K3 yang paling besar cukup baik dan penyebab timbulnya kecelakaan kerja yang paling banyak adalah kurangnya kesadaran pekerja itu sendiri sedangkan aturan yang diterapkan cukup baik. Untuk fasilitas APD yang sering digunakan helm proyek sampai dan taat pada rambu-rambu K3. Artinya program-program penerapan K3 pada proyek sudah dilaksanakan dengan baik.
\end{abstract}

Kata Kunci : keselamatan dan kesehatan kerja, konstruksi, proyek, penyebaran kuesioner, hasil penelitian.

\section{PENDAHULUAN}

Perusahaan jasa kontruksi memiliki resiko bahaya, seperti menggunakan peralatan berat, mesin potong, las, bekerja di tempat tinggian, suhu tinggi, dan lain-lain. Tersedianya 
Sistem Manajemen Keselamatan dan Kesehatan Kerja datau Occupational Health and Safety Manajement System (SMK3/OHSMS) system ini diperlukan untuk meminimalisir resiko. Untuk memberikan kepuasan pelanggan dan perlindungan keamanan kepada karyawan dan keselamatan dan kesehatan kerja serta menjaga kelestarian lingkungan hidup. Sudah menjadi kebijakan direksi KSO PT. SATRIAMAS KARYATAMA - PT. GALA TAMA agar setiap karyawan dan pekerja mendapatkan tempat yang aman dan sehat dalam melaksanakan tugas sehari-hari.

Pelaksanaan proyek pembangunan gedung ini dilaksanakan di Jl. A. Yani No. 139 Kota Semarang, dikerjakan oleh kontraktor KSO. PT. Satriamas Karyatama - PT. Gala Tama. Berlokasi ditempat yang memiliki tingkat kerawanan yang tinggi terhadap kemungkinan terjadinya kecelakaan kerja seperti, terkena arus listrik, terkena benda tajam, kejatuhan benda dan lain-lain. Berdasarkan uraian diatas maka tujuan dari penelitian ini adalah untuk menganalisis Penerapan Keselamatan dan Kesehatan Kerja (K3 ). Pada Pekerjaan Pembangunan Gedung Tahap II Kanwil Dirjen Bea dan Cukai Jawa Tengah dan D.I. Yogyakarta.

\section{METODOLOGI PENELITIAN}

Pada penelitian ini akan menganalisa lebih lanjut bagaimana tentang penerapan dan pemakaian K3 pada suatu proyek konstruksi. Dimana lokasi ini terletak di wilayah kota Semarang. Pengumpulan data pun dilakukan dengan cara survey mengambil sample beberapa pekerja dan staff pada Proyek Pembangunan Gedung Tahap II Kanwil Dirjen Bea dan Cukai Jawa Tengah dan D.I. Yogyakarta. Untuk memperoleh data dari penelitian ini, penulis mengambil dari dua data yaitu data primer dan data sekunder. Bagan alir penelitian ditunjukkan pada gambar 1.

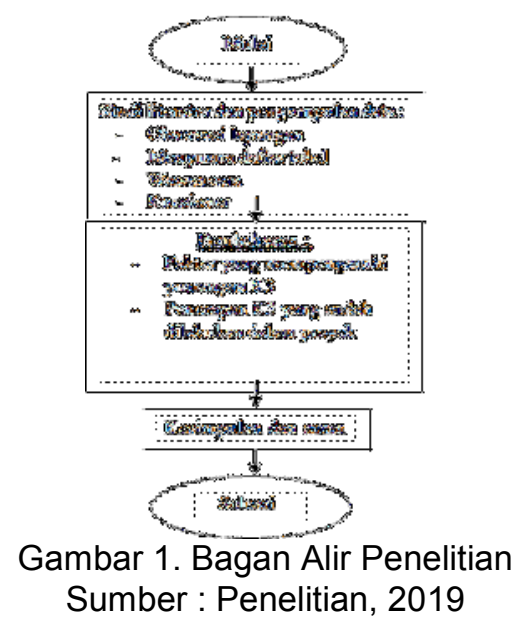

\section{ANALISIS DAN PEMBAHASAN}

Pada analisis dan pembahasan responden dalam penelitian ini adalah pihak dari kontraktor pada Proyek Pembangunan Gedung Tahap II Kanwil Dirjen Bea dan Cukai Jawa Tengah dan D.I. Yogyakarta yang terletak di JI. A. Yani No. 139 Kota Semarang, dikerjakan oleh kontraktor KSO. PT. Satriamas Karyatama - PT. Gala Tama. Jumlah responden yang diambil sebanyak 35 responden yang terdiri dari staff karyawan dan pekerja. Klasifikasi Jabatan Responden Pada Proyek Pembangunan Gedung Tahap II Kanwil Dirjen Bea dan Cukai Jawa Tengah dan D.I. Yogyakarta tertera pada tabel 1. Sedangkan rumus yang digunakan sebagai berikut :

$\bar{X} \quad=\frac{\sum_{i=1}^{n} \mathrm{x}_{\mathrm{i}}}{\eta}$

Keterangan :

$\bar{X} \quad=$ Rata-rata ukuran nilai faktor. 
$\mathrm{X} i \quad=$ Nilai sampel ke $\mathrm{i}$

$n \quad=$ Jumlah sampel

$\mathrm{IKR}=\frac{\bar{X}}{m}$

Keterangan :

$\bar{X} \quad=\mathrm{Ra}$

Setelah nilai mean dan rangking diketahui,kemudian menentukan range untuk megelompokkan masing-masing variabel. Dengan mengajukan 4 pilihan yang sesuai dengan tingkat kepentingan dan untuk kepentingan di lapangan.ta-rata ukuran nilai faktor.

$\mathrm{IKR} \quad=$ Indeks kepentingan relative.

$m \quad$ = Jangkauan nilai faktor.

Setelah nilai mean dan rangking diketahui,kemudian menentukan range untuk megelompokkan masing-masing variabel. Dengan mengajukan 4 pilihan yang sesuai dengan tingkat kepentingan dan untuk kepentingan di lapangan. Menentukan interval dari yang tidak digunakan sampai yang sangat sering digunakan dengan kriteria skor hasil analisa sebagai berikut :

a. Skor 3,25<X $\leq 4,00=$ Faktor sangat sering digunakan.

b. Skor $2,50<X \leq 3,25=$ Faktor sering digunakan.

c. Skor $1,75<\mathrm{X} \leq 2,50=$ Faktor jarang digunakan.

d. Skor $1,00<X \leq 1,75=$ Faktor tidak digunakan.

Berdasarkan urutan rangking skor nantinya diambil 4 variabel yang berpengaruh dengan melihat rangking nilai teratas dari nilai faktor yang keluar didalam analisa tersebut. Klasifikasi Kecelakaan Kerja Pada Proyek Pembangunan Gedung Tahap II Kanwil Dirjen Bea dan Cukai Jawa Tengah dan D.I. Yogyakarta ditentukan berdasarkan skor hasil analisis sebagai berikut :

a. Skor $3,25<X \leq 4,00=$ Faktor sangat sering terjadi.

b. Skor $2,50<X \leq 3,25=$ Faktor sering terjadi.

c. Skor $1,75<X \leq 2,50=$ Faktor cukup sering terjadi.

d. Skor $1,00<X \leq 1,75=$ Faktor tidak pernah terjadi.

Berdasarkan urutan rangking skor nantinya diambil 4 variabel yang berpengaruh dengan melihat rangking nilai teratas dari nilai faktor yang keluar di dalam analisis tersebut.

Tabel 1. Jabatan Responden

\begin{tabular}{c|l|c}
\hline No & Jabatan & Jumlah \\
\hline 1 & Responden & 1 \\
2 & Site Manager Manager & 1 \\
3 & Pelaksana & 4 \\
4 & Mandor & 4 \\
5 & Pekerja & 25 \\
\hline & Jumlah & 35 \\
\hline
\end{tabular}

Hasil kuesioner ditunjukkan pada gambar 2 dan tabel 2,3,4,5.

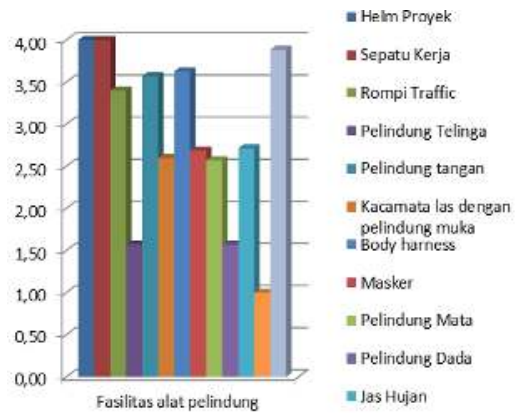


Gambar 2. Bagan Alir Penelitian

Sumber : Penelitian, 2019

Tabel 2. Skor Fasilitas Alat Pelindung Diri yang ada pada Pembangunan Gedung yang sering dipakai

\begin{tabular}{lllll}
\hline No & \multicolumn{1}{c}{ Fasilitas alat pelindung } & Mean & IKR & Keterangan \\
\hline 1 & Helm Proyek & 4,00 & 1,00 & Sangat Sering Digunakan \\
2 & Sepatu Kerja & 4,00 & 1,00 & Sangat Sering Digunakan \\
3 & Rompi Traffic & 3,40 & 0,85 & Sangat Sering Digunakan \\
4 & Pelindung Telinga & 1,57 & 0,39 & Tidak Digunakan \\
5 & Pelindung tangan & 3,57 & 0,89 & Sangat Sering Digunakan \\
6 & Kacamata las dengan pelindung & 2,60 & 0,65 & Sering Digunakan \\
7 & muka & 3,63 & 0,91 & Sangat Sering Digunakan \\
8 & Body harness & 2,69 & 0,67 & Sering Digunakan \\
9 & Masker & 2,57 & 0,64 & Sering Digunakan \\
10 & Pelindung Mata & 1,57 & 0,39 & Tidak Digunakan \\
11 & Jas Hujan & 2,71 & 0,68 & Sering Digunakan \\
12 & Pelampung & 1,00 & 0,25 & Tidak Digunakan \\
13 & Rambu-rambu dan Tanda K3 & 3,89 & 0,97 & Sangat Sering Digunakan \\
\hline \multirow{2}{*}{ Mean Total } & & 37,20 & \\
\hline
\end{tabular}

Sumber : Analisis Peneliti, 2019

Tabel 3. Skor Intensitas Klasifikasi Kecelakaan Kerja yang Sering Terjadi pada Proyek Menurut Jenis kecelakaan

\begin{tabular}{|c|c|c|c|c|}
\hline No & $\begin{array}{l}\text { Intensitas klasifikasi kecelakaan kerja yang } \\
\text { sering terjadi menurut jenis kecelakaan }\end{array}$ & Mean & IKR & Keterangan \\
\hline 1 & $\begin{array}{l}\text { Kontak dengan bahan-bahan yang } \\
\text { berbahaya atau radiasi }\end{array}$ & 1,17 & 0,29 & $\begin{array}{l}\text { Tidak Pernah } \\
\text { Terjadi }\end{array}$ \\
\hline 2 & Tertimpa benda jatuh & 1,29 & 0,32 & $\begin{array}{l}\text { Tidak Pernah } \\
\text { Terjadi }\end{array}$ \\
\hline 3 & Terjepit oleh benda bergerak & 1,14 & 0,29 & $\begin{array}{l}\text { Tidak Pernah } \\
\text { Terjadi }\end{array}$ \\
\hline 4 & Gerakan yang dipaksakan & 1,17 & 0,29 & $\begin{array}{l}\text { Tidak Pernah } \\
\text { Terjadi }\end{array}$ \\
\hline 5 & Terkena arus listrik & 1,29 & 0,32 & $\begin{array}{l}\text { Tidak Pernah } \\
\text { Terjadi }\end{array}$ \\
\hline 6 & Terkena suhu tinggi & 1,09 & 0,27 & $\begin{array}{l}\text { Tidak Pernah } \\
\text { Terjadi }\end{array}$ \\
\hline 7 & Terjatuh & 1,31 & 0,33 & $\begin{array}{l}\text { Tidak Pernah } \\
\text { Terjadi }\end{array}$ \\
\hline & Mean Total & \multicolumn{2}{|c|}{8,46} & \\
\hline
\end{tabular}


Tabel 4. Skor Intensitas Klasifikasi Kecelakaan Kerja yang Sering Terjadi pada Proyek Menurut Penyebab kecelakaan

\begin{tabular}{|c|c|c|c|c|}
\hline No & $\begin{array}{l}\text { Intensitas klasifikasi kecelakaan kerja } \\
\text { yang sering terjadi menurut penyebabnya }\end{array}$ & Mean & IKR & Keterangan \\
\hline 1 & Mesin & 1,31 & 0,46 & $\begin{array}{l}\text { Tidak Pernah } \\
\text { Terjadi }\end{array}$ \\
\hline 2 & Alat angkut dan alat angkat & 1,34 & 0,51 & $\begin{array}{l}\text { Tidak Pernah } \\
\text { Terjadi }\end{array}$ \\
\hline 3 & $\begin{array}{l}\text { Peralatan lain (bejana bertekanan, tangga, } \\
\text { perancah dan lain-lain). }\end{array}$ & 1,43 & 0,53 & $\begin{array}{l}\text { Tidak Pernah } \\
\text { Terjadi }\end{array}$ \\
\hline 4 & Bahan-bahan, zat-zat dan radiasi & 1,26 & 0,45 & $\begin{array}{l}\text { Tidak Pernah } \\
\text { Terjadi }\end{array}$ \\
\hline 5 & Lingkungan kerja & 1,20 & 0,41 & $\begin{array}{l}\text { Tidak Pernah } \\
\text { Terjadi }\end{array}$ \\
\hline & Mean Total & \multicolumn{2}{|c|}{6,54} & \\
\hline
\end{tabular}

Sumber : Analisis Peneliti, 2019

Tabel 5. Skor Faktor yang Mempengaruhi Penerapan K3 pada Proyek

\begin{tabular}{|c|c|c|c|c|c|}
\hline No & $\begin{array}{l}\text { Faktor - faktor yang Mempengaruhi Penera } \\
\text { Pada Proyek }\end{array}$ & an $\mathrm{K} 3$ & Mean & Rangking & $\begin{array}{l}\text { Ketera } \\
\text { ngan }\end{array}$ \\
\hline 1 & $\begin{array}{l}\text { Komitment dan dukungan manajemen } \\
\text { kontraktor }\end{array}$ & 3,11 & 0,78 & Berpengaruk & \\
\hline 2 & Kompetensi yang dimiliki pekerja & 3,17 & 0,79 & \multirow{4}{*}{\multicolumn{2}{|c|}{$\begin{array}{l}\text { Berpengaruh } \\
\text { Sangat berpengaruh } \\
\text { Sangat berpengaruh } \\
\text { Sangat berpengaruh }\end{array}$}} \\
\hline 3 & Pelatihan yang diajarkan kepada pekerja & 3,49 & 0,87 & & \\
\hline 4 & Kesadaran pekerja terhadap penerapan K3 & 3,69 & 0,92 & & \\
\hline 5 & $\begin{array}{l}\text { Persiapan dan respon tanggap darurat oleh } \\
\text { manajemen kontraktror }\end{array}$ & 3,46 & 0,86 & & \\
\hline 6 & Pemantauan dan pengukuran kinerja K3 & 3,66 & 0,91 & \multirow{2}{*}{\multicolumn{2}{|c|}{$\begin{array}{l}\text { Sangat berpengaruh } \\
\text { Sangat berpengaruh }\end{array}$}} \\
\hline 7 & $\begin{array}{l}\text { Tindakan perbaikan kedisiplinan para } \\
\text { pekerja }\end{array}$ & 3,83 & 0,96 & & \\
\hline 8 & $\begin{array}{l}\text { Ketidaksesuaian skill pekerja dengan } \\
\text { pekerjaannya }\end{array}$ & 3,63 & 0,91 & \multicolumn{2}{|c|}{ Sangat berpengaruh } \\
\hline 9 & $\begin{array}{l}\text { Penyelidikan insiden oleh manajemen jika } \\
\text { terjadi kecelakaan kerja }\end{array}$ & 3 & 0 & \multicolumn{2}{|c|}{ Sangat berpengaruh } \\
\hline 10 & Keadaan lingkungan kerja & 3,57 & 0,89 & \multirow{2}{*}{\multicolumn{2}{|c|}{$\begin{array}{l}\text { Sangat berpengaruh } \\
\text { Sangat berpengaruh }\end{array}$}} \\
\hline 11 & $\begin{array}{l}\text { Peralatan yang digunakan pekerja dalam } \\
\text { bekerja }\end{array}$ & 3,40 & 0,85 & & \\
\hline 12 & Kondisi fisik tenaga kerja & 3,74 & 0 , & \multirow{2}{*}{\multicolumn{2}{|c|}{$\begin{array}{l}\text { Sangat berpengaruh } \\
\text { Sangat berpengaruh }\end{array}$}} \\
\hline 13 & Kondisi psikologis tenaga kerja & 3,69 & 0,92 & & \\
\hline
\end{tabular}

Sumber : Analisis Peneliti, 2019

Berdasarkan tabel 2, 3, 4, 5 dan gambar 2 hasil penelitian dengan menggunakan kuisioner Penerapan K3 pada Pekerjaan Pembangunan Gedung Tahap II Kanwil Dirjen Bea dan Cukai Jawa Tengah dan D.I Yogyakarta telah diterapkan dengan baik dan sesuai prosedur. Dari hasil penelitian 35 responden ini, sebagian besar responden adalah pekerja dengan presentase $62.8 \%$ dan berpengalaman lebih dari lima tahun dengan usia 20-50 tahun dan sebagian besar berpendidikan SMA/SMK dengan presentase $60 \%$. Untuk penilaian jaminan K3 yang paling besar adalah cukup baik, dan penyebab timbulnya kecelakaan kerja yang paling banyak adalah kurangnya kesadaran pekerja itu sendiri sedangkan aturan K3 yang diterapkan cukup baik. Untuk pertanyaan klasifikasi jenis kecelakaan yang sering terjadi dilingkungan kerja adalah tertimpa benda jatuh, sedangkan mesin adalah penyebab kecelakaan kerja yang sering terjadi. Untuk 
pertanyaan pentingnya penerapan $\mathrm{K} 3$ dalam proyek konstruksi sebagian besar menjawab sangat penting dan dilaksanakan dengan baik karena pada setiap proyek selalu terjadi kecelakaan kerja. Sedangkan fasilitas alat pelindung diri yang sering digunakan adalah helm proyek, sepatu kerja, rompi, pelindung tangan, body harness dan rambu-rambu K3. Untuk pertanyaan intensitas klasifikasi kecelakaan kerja yang sering terjadi pada proyek adalah terjatuh. Sedangkan untuk penyebabnya peralatan lain (bejana bertekanan, tangga, perancah dan lain-lain) adalah yang sering terjadi. Untuk pertanyaan faktor-faktor yang mempengaruhi penerapan K3 nilai yang paling tinggi adalah tindakan perbaikan kedisiplinan para pekerja dengan skor nilai 3.83, yang artinya program perbaikan terhadap kedisiplinan para pekerja sudah sangat baik dilakukan agar kemungkinan terjadinya kecelakaan pada pekerja sendiri dapat diminimalisir, kondisi fisik tenaga kerja dengan skor 3.74, yang artinya sangat berpengaruh terhadap keamanan pekerja itu sendiri, kesadaran pekerja terhadap penerapan K3 dengan skor 3.69, bahwa penerapan standar K3 dimulai dari diri pekerja itu sendiri akan pentingnya keselamatan dan kesehatan kerja, dan untuk kondisi psikologis tenaga kerja mendapat skor 3.69, artinya kondisi kejiwaan pekerja sangat berpengaruh terhadap kenyamanan dalam bekerja.

\section{KESIMPULAN}

Penerapan K3 pada proyek Pekerjaan Pembangunan Gedung Tahap II Kanwil Dirjen Bea dan Cukai Jawa Tengah dan D.I Yogyakarta tersebut sangat berpengaruh dan dapat ditindak lanjuti dengan baik. Sebagian besar responden adalah pekerja dengan presentase $62.8 \%$ dan berpengalamdengan pengalaman lebih dari lima tahun dan usia 20-50 tahun serta sebagian besar berpendidikan SMA sederajat dengan presentase $60 \%$. Untuk jaminan K3 yang paling besar cukup baik, sedamgkan timbulnya kecelakaan kerja yang paling banyak adalah kurangnya kesadaran pekerja itu sendiri. Untuk fasilitas APD yang sering digunakan helm proyek sampai dan taat pada rambu-rambu K3. Artinya program-program penerapan K3 pada proyek sudah dilaksanakan dengan baik. Penelitian ini juga menjelaskan tentang standar operasional prosedur yang harus diikuti dan penanganan maupun dampak atau resiko yang akan terjadi pada proyek konstruksi jika tidak mematuhi aturan-aturan yang menjelaskan tentang keselamatan kerja.

\section{DAFTAR PUSTAKA}

Atmoko, T. (2012). Standart Operasional Prosedur (SOP) dan Akuntabilitas Kinerja Instansi Pemerintah.

Himpunan Peraturan Perundang-Undangan Republik Indonesia. (2008), Keselamatan dan Kesehatan Kerja (K3), Nuansa Aulia, Bandung.

Kuswana, W.S. (2015), Mencegah Kecelakaan Kerja, Bandung, PT. Remaja Rosdakarya.

Lembaga Negara Republik Indonesia. (2012), Peraturan Pemerintah Republik Indonesia Nomor 50 Tahun 2012 tentang Penerapan Sistem Manajemen Keselamatan dan Kesehatan Kerja. Indonesia, 15 Oktober 2017.

Lembaga Negara Republik Indonesia. (2015), Peraturan Pemerintah Republik Indonesia Nomor 44 Tahun 2015 Tentang penyelenggaraan Program Jaminan Kecelakaan Kerjadan Jaminan Kematian Indonesia, 20 Oktober 2017.

Menteri Ketenagakerjaaan dan Transmigrasi. (2014), Peraturan Menteri Ketenagakerjaan Republik Indonesia Nomor 26 Tahun 2014 tentang Penyelenggaraan Penilaian Penerapan Sistem Manajemen Keselamatan Dan Kesehatan Kerja Indonesia, 20 Oktober 2017.

Menteri Ketenagakerjaan Republik Indonesia. (2016), Peraturan Menteri Ketenagakerjaan Republik Indonesia Nomor 11 Tahun 2016 Tentang Pelayanan Kesehatan dan Besaran Tarif dala Penyelenggaraan Program Jaminan Kecelakaan Kerja Indonesia, 30 November 2017. 
Menteri Ketenagakerjaan Republik Indonesia. (2012), Peraturan Pemerintah Republik Indonesia Nomor: 50 Tahun 2012 Tentang Penerapan Sistem Manajemen Keselamatan dan Kesehatan Kerja, Jakarta.

Solihah, Q., dan Kuncoro, W. (2013), Keselamatan dan Kesehatan Kerja (Konsep, Perkembangan, dan Implementasi Budaya Keselamatan), Jakarta: Penerbit Buku Kedokteran EGC. 